\title{
Etiology Agents and Antibiotic Susceptibility profile of Cerebrospinal Meningitis: Retrospective Description of Surveillance Data in Rwanda
}

\author{
Celestin Musabyumuremyi ${ }^{\mathrm{a}}$, Therese Umuhoza ${ }^{\mathrm{b}}$, Ella Larissa Ndoricyimpaye ${ }^{\mathrm{c}}$, Gilbert Ntaganira ${ }^{\mathrm{a}}$, \\ Naasson Tuyiringire ${ }^{\mathrm{d}}$ \\ ${ }^{\text {aR }}$ wanda Biomedical Center, National Reference Laboratory Division \\ bInstitute of Tropical and Infectious Diseases at University of Nairobi \\ ${ }^{\mathrm{c} S}$ School of Allied Health Sciences, College of Medicine and Health Sciences, University of Rwanda \\ ${ }^{\mathrm{d}}$ School of Nursing and Midwifery, College of Medicine and Health Sciences, University of Rwanda. \\ *Correspondence to Celestin Musabyumuremyi (cemusabu@gmail.com)
}

\begin{abstract}
Background: Cerebrospinal meningitis is an important cause of morbidity and mortality globally, but its highest burden is in sub-Saharan Africa. Surveillance is critical to assess the burden of the disease and provide the necessary information to mitigate the impact. The aim of this study is to assess the cases of Cerebrospinal meningitis occurring across the Rwanda in order to determine where the burden of illness lies, the causative agents and effective treatments.

Method: A retrospective study was carried out from January 2010 to December 2016. 173 cerebrospinal fluid samples from 25 Districts Hospitals in Rwanda were collected from patients suspected of meningitis. Demographic characteristics, region and season, etiological agents, antimicrobial susceptibility variables were analyzed with SPSS, version 22 .

Results: Out of 173 suspected cases, 68 were positive for cerebrospinal meningitis. Of the positive cases 35 (56.1\% were male) and $17(25 \%)$ were under 5 years of age. The majority of cases $27(37.5 \%)$ occurred between June and September and $22(32 \%)$ were found in the eastern region. In this sample $32(47.1 \%)$ of the confirmed cases were caused by Streptococcus pneumonia, followed by Neisseria meningitidis 17 (x/y; 25.1\%) and E. coli with 3 (4.5\%). Two different fungi, Cryptococcus neoformans and Candida albicans represented $3(4.4 \%)$ of causative agents. The most common treatment was Ceftriaxone which was the most active/sensitive to all bacterial agents.

Conclusion: Children under 5 years of age are the most affected, and the higher prevalence occurs during the dry season in the eastern region. Streptococcus pneumoniae was the leading cause of meningitis, and ceftriaxone antibiotic was the most active to the majority of identified bacteria.
\end{abstract}

Key words: Antibiotics, Cerebrospinal meningitis, Retrospective data, Rwanda, Susceptibility.

\section{INTRODUCTION}

$\mathrm{M}$ eningitis is the inflammation of meninges affecting the arachnoid, and subarachnoid that occurs in response to infections or non-infections causes. Infectious causes of meningitis include bacteria, viruses, fungi, parasites. Non-infectious meningitis may be due to sarcoidosis, systemic lupus erythematous, tumor, and leukemia. ${ }^{1}$ Bacterial meningitis is a very common and fatal disease causing a significant morbidity and mortality globally. According to the World Health Organization (WHO) 1.2 million cases of bacterial meningitis are

East Africa Science 2020| Volume 2 | Number 1 estimated to occur every year with 170,000 deaths worldwide. ${ }^{1,2}$ In 2010, the WHO reported that 15,000 deaths from bacterial meningitis occurred in Europe, 18,000 in America, 20,000 in Africa, and 73,000 in South East Asia ${ }^{1}$. The Africa meningitis belt includes parts of 26 countries and within this zone; the burden of the disease is usually the highest in the world, with an incidence rate of 7000 to 18000 annually. There is a clear seasonal pattern of the disease, with most cases being seen in the first 6 months of the year, specifically in the dry season. ${ }^{3}$ Studies report that airborne dust $^{3}$ and higher temperatures ${ }^{3}$ increase the risks of transmission. Newborns, people 
living in low-income countries, and those with immunecompromised conditions are at risk for high mortality and morbidity. ${ }^{4,5}$ The disease circulates through direct contact in the form of person to person contact, through kissing, droplets, sneezing and coughing. ${ }^{5}$ Morbidity and mortality associated with bacterial meningitis is increased by the presence of antimicrobial-resistant organisms and incomplete knowledge of the pathogenesis ${ }^{6}$. Suspected bacterial meningitis is a medical emergency and immediate steps must be taken to establish specific diagnosis and treatment.

Most cases of bacterial meningitis are caused by Streptococcus pneumonia, Streptococcus agalactiae, Neisseria meningitides, Listeria monocytogenes, and Hemophilus influenza B. ${ }^{7,8,9}$ Bacterial meningitis reaches the subarachnoid space through the hematogenous route or may directly reach the meninges with a parameningeal focus of infection. ${ }^{8,9}$ Bacterial meningitis can cause brain damage, hearing loss, limb amputation, learning disabilities, and even death. Fungi can cause severe infections but are much less frequent than bacterial or viral infections. 9, 10 The most common causes of fungi meningitis are Cryptococcus neoformans, Candida albicans, and Aspergillus species especially, in immunocompromised patients. $^{10}$ Cryptococcus neoformans is of medical importance as it is capable of crossing the blood-brain barrier and causing meningitis in both immunocompetent and immunocompromised individuals. ${ }^{11,12}$ Permanent neurological sequelae such as hearing loss, mental retardation, deafness, blindness, seizures disorders, and behavioral changes may occur up to $50 \%$ of survivors even after receiving antimicrobial therapy. ${ }^{13}$ Prevention of bacterial meningitis can be achieved through vaccinations. Effective vaccines are available against the most common causative agents. These include $H$. influenza type $b$, Streptococcus pneumonia, and Neisseria meningitides serogroups: A, B, $\mathrm{C}, \mathrm{W} 135$, and $\mathrm{Y}^{14}$. In the event of infection then early diagnosis and proper case management including prompt treatment with appropriate antibiotics is needed to mitigate poor outcomes.

The African meningitis belt region stretches from Senegal in the west to Ethiopia in the east. However, the burden goes beyond this area. The causative agent of meningitis, the mortality and morbidity vary by age and geographical location. Rwanda is not included in meningitis regions. Nevertheless, cases of suspected meningitis have been reported. We therefore, conducted this retrospective study to understand the disease dynamics in the Rwandan setting. Specifically, we determined the bacterial causative agent, antibiotic susceptibility, and the spatial distribution of the affected age groups with the aim of providing evidence to support the establishment of effective preventive measures.

\section{METHODS}

In this study we retrospectively analyzed 173 Cerebrospinal Fluid (CSF) samples that had been collected from 25 District Hospitals in Rwanda between the periods of January 2010 to December 2016. All 173 cerebrospinal fluid samples were collected from patients suspected of meningitis, based on clinical signs and symptoms for bacterial meningitis, which included nausea and vomiting, headache and stiff neck, confusion, and loss of hearing.

\section{Sample Collection}

The CSF samples were obtained using standard guidelines for sterile clinical procedures. Before lumbar puncture procedure, the patients were made to lie down at an appropriate position, the skin was disinfected along a line drawn between the crests of the two ilia with $70 \%$ alcohol and iodine and allowed to dry completely .The clinician then injected the spinal needle into the skin between the 4 and 5th lumbar vertebral spines with the bevel of the needle facing up.

As soon as the needle was in position, the CSF pressure was measured and a sample of 3 to $4 \mathrm{ml}$ of the fluid was collected in two sterile screw tubes for testing .Specimens were allowed to stand on the table for five minutes and inspected for colour change or 'cobweb' formation and subsequently delivered to the laboratory within half an hour after sample collection. One container was analyzed in the bacteriology laboratory in which the sample was collected and the second was sent to the National Reference Laboratory for confirmation and quality control

\section{CSF Sample Processing}

The initial processing of CSF was started by recording the volume of CSF and its macroscopic appearance. The CSF was spun to sediment cells and bacteria. The films of sediments were stained by Gram's stain technique and examined microscopically.

\section{Culture}

Samples were processed according to the standard microbiological procedures by inoculating on blood agar, chocolate agar plates, and incubated at $35^{\circ} \mathrm{C}$ to in presence of $5 \%$ Carbone dioxide for the growth of fastidious bacteria, MacConkey agar, and sabouraud dextrose agar incubated aerobically at $35^{\circ} \mathrm{C}-37^{\circ} \mathrm{C}$. After $18-24$ hours of incubation, the plates were observed for bacterial growth; those that showed no growth were further incubated for another 24 hours. The plates were examined for the presence of bacterial growth, and isolates were identified by standard microbiological methods including but not 
limited to colony morphology, staining, serological typing, and biochemical test ${ }^{16}$. The disc diffusion method was performed for the antibiotic sensitivity on pure plates for penicillin, oxacillin, ceftriaxone, erythromycin, and trimethoprim-sulfamethoxazole. The selection of the panel of antimicrobials used for testing was based on the guidelines from the Clinical and Laboratory Standards Institute. ${ }^{16}$ The inhibition diameter zones were measured around antibiotics disc were measured and interpreted as sensitive, intermediate, or resistant (for the details refer to the Clinical and Laboratory Standards Institute antimicrobial susceptibility testing, CLSI).$^{16}$

Secondary data obtained using the methods described were analyzed and presented to map the dynamic of cerebrospinal meningitis cases identified in Rwanda from 2010 to 2016 . Note that the authors conducted the methods during this period.

Data were retrieved from National Reference Laboratory logbook and entered into Microsoft excel spreadsheet. Percentage and Chi-square were calculated using SPSS, version 22. Demographic characteristics, region and season, etiological agents, antimicrobial susceptibility variables were extracted. Using MS-Excel 2013, we analyzed data in terms of person (age and sex), place (district), time (months and years), and types of causative organisms identified among confirmed. Results were illustrated by graphs and frequency distributions generated for key variables.

\section{Ethical consideration}

Initial the data have been collected for therapeutic purpose but in order to improve the quality of surveillance, we have shared the data. To ensure confidentiality, we used coded patient identification numbers in place of names. Data held on computers were encrypted with a password.

\section{RESULTS}

The data below presents the results according to the age, region, bacterial profile, antibiotic sensitivity of each of the 68 positive cases that were identified.

\section{Age distribution of cases}

The highest proportion of cases was amongst patients under 5 years of age $(17 / 68 ; 25 \%)$ followed by $6-10$ year olds (14/68; 20.6\%) (Table 1).

\section{Geographical distribution of cases}

The highest proportion of cases came from the eastern province $(22 / 68 ; 32 \%)$ followed by the western province with a frequency $(18 / 68 ; 26 \%)$. Figure 1 illustrates the geographical spread of the 68 cerebrospinal meningitis cases across the provinces in Rwanda

\section{TABLE 1. Distribution of the confirmed positive cases according to the age}

\begin{tabular}{lcc}
\hline Age & Frequency & Percentage \\
\hline Under 5 years & 17 & 25.0 \\
$6-10$ & 14 & 20.6 \\
$11-15$ & 9 & 13.2 \\
$16-20$ & 10 & 14.7 \\
$21-25$ & 2 & 2.9 \\
$26-30$ & 3 & 4.4 \\
$31-35$ & 5 & 7.4 \\
$36-40$ & 1 & 1.5 \\
$41-45$ & 4 & 5.9 \\
Over 45 & 3 & 4.4 \\
\hline Total & $\mathbf{6 8}$ & $\mathbf{1 0 0}$ \\
\hline
\end{tabular}


FIGURE 1. Distribution of positive meningitis according to the provinces in Rwanda

\section{Etiology agents of cases}

The most common pathogens isolated responsible for meningitis in this sample was Streptococcus pneumonia $(32 / 68 ; 47.1 \%)$, followed by Neisseria meningitis W135 $(17 / 68 ; 25.1 \%)$ and E. coli $(3 / 68 ; 4.5 \%)$. The $16(23.3 \%)$ remaining cases were caused by other pathogens including fungi Cryptococcus neoformans and Candida albicans (Table 2).

\section{Antibiotic susceptibility profile}

Antimicrobial susceptibility pattern of isolated bacterial pathogens was performed by Kirby Bauer disc diffusion method according to the guidelines of the Clinical and Laboratory Standards Institute ${ }^{16}$. Inoculum was prepared by picking parts of two or three identical colonies with a sterile wire loop. This was suspended in sterile peptone water (broth) and incubated up to two hours to allow organisms to reach their log phase of growth. The density of suspension to be inoculated was determined by comparison with the opacity standard on McFarland 0.5 Barium sulphate. Sterile swab was dipped into the suspension of the isolate in the peptone water, squeezed free from excess fluid against the side of bottle and spread over the Mueller -Hinton agar plate. The test organism and the standard control from the broth were spread evenly over the surface of the Mueller -Hinton agar using sterile cotton wool swabs. Sensitivity discs for appropriate drugs were placed onto the media and incubated at $37^{\circ} \mathrm{C}$ for $24 \mathrm{hrs}$. After 24 hours each plate was examined and growth zones were measured to the nearest millimeter, using sliding caliper which was held at the back of the inverted media plate. The results of drug susceptibility of tested antibiotics to the isolates are presented in (Table 3).

\section{The season}

We found that in this sample the largest proportion of cases occurred prevalence of in the summer between June and September in Rwanda (Figure 2). 
TABLE 2. Distribution of isolated pathogens among cerebrospinal meningitis confirmed cases

\begin{tabular}{lcc}
\hline Bacteria & Frequency & Percentage \\
\hline S. pneumonia & 32 & 47.1 \\
N. Meningitidis W135 & 17 & 25.1 \\
E. coli & 3 & 4.5 \\
S. aureus & 3 & 4.5 \\
C. neoformans & 2 & 3 \\
H. influenza B & 2 & 3 \\
L. monocytogenes & 2 & 3 \\
C. albicans & 1 & 1.4 \\
H. para influenza & 1 & 1.4 \\
P. aeruginosa & 1 & 1.4 \\
E. cloacae & 1 & 1.4 \\
S. xylosus & 1 & 1.4 \\
S. lugdunens & 1 & 1.4 \\
S. enteritidis & 1 & 1.4 \\
\hline Total & $\mathbf{6 8}$ & $\mathbf{1 0 0}$ \\
\hline
\end{tabular}

TABLE 3. Susceptibilities of isolated Bacteria to antibiotics (in mm)

\begin{tabular}{lccccc}
\hline Antibiotics/Resistance & S. pneumoniae & N. meningitis & E. coli & H. influenza B & S. aureus \\
& \multicolumn{1}{c}{$\boldsymbol{w 1 3 5}$} & & & \\
\hline Penicillin & 60.1 & 55.3 & 68.5 & 71.3 & 74.5 \\
Oxacyllin & 80.5 & 92.8 & 75.6 & 80.6 & 71.1 \\
Ceftriaxone & 95.5 & 98.6 & 92.8 & 97.6 & 98.5 \\
Erythromycin & 87.6 & 89.7 & 90.8 & 92.7 & 97.7 \\
Cefotaxime & 87.7 & 96.7 & 98.9 & 99.3 & 86 \\
Trimethoprim & 92.5 & 97.4 & 98 & 75.3 & 80.4 \\
Sulfamethazole & 76.1 & 83.2 & 88.5 & 91.5 & 87 \\
\hline
\end{tabular}

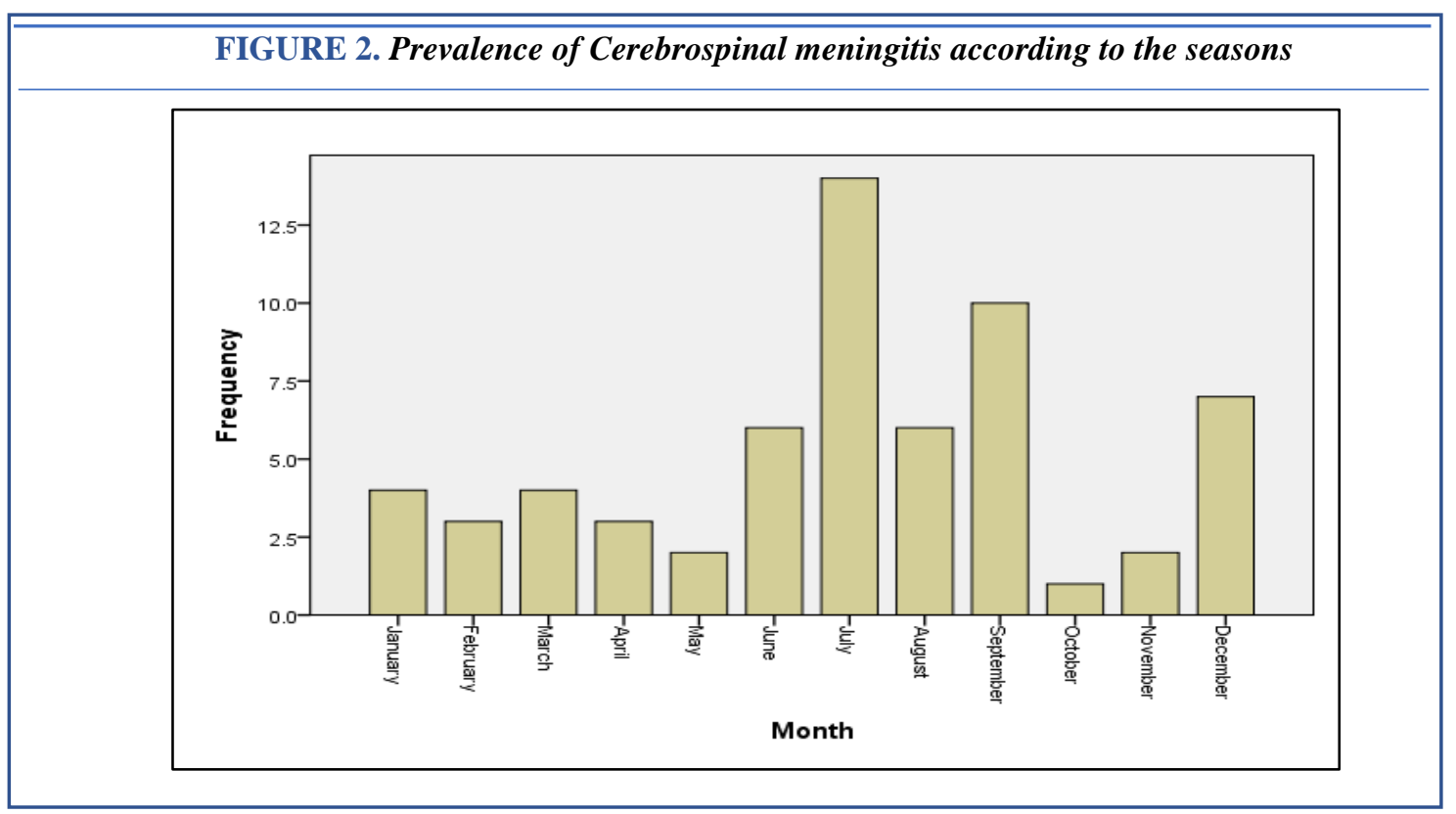




\section{DISCUSSION}

Meningitis is a serious infection and is associated with considerable mortality and morbidity in various parts of the world, with sub Saharan African countries bearing the highest burden of disease. Rwanda is located in eastern African and borders the African meningitis belt. Surveillance of meningitis is crucial to ascertain the real situation of cases and to provide evidence needed for treatment and prevention strategies. This study found that bacterial agents (specifically Streptococcus pneumonia) were the most common causes of meningitis in a sample of 68 cases obtained from across the country between 2010 and 2016 and sensitivity to antibiotics remained high. In this sample of confirmed cases, $56.1 \%$ were males, and amongst those under 5 years of age (17/68; $25 \%$ ), finally cases were mainly recorded between June and September. Studies from other regions around the world have also found a higher prevalence of meningitis amongst males. ${ }^{17}$ A study of the characteristic of bacterial meningitis in four major tertiary care hospitals in Bangladesh during 2003 and 2004 showed that out of 1841 cases, 71\% (1307) were male ${ }^{19}$. Similarly, studies conducted in Ethiopia also reported a higher incidence in males. ${ }^{17}$ In our study most cases were amongst children less than 10 years of age, which is similar to findings reported in a study conducted in North Ethiopian during 2001- 2002. ${ }^{17,} 18$ Bacterial meningitis is known to affect children ${ }^{16}$. Mortality amongst this age group from this cause is also high ${ }^{1,2,16}$ therefore highlighting the importance of early childhood immunization ${ }^{1,4}$ and rapid identification and treatment strategies to mitigate the impact of the disease. Our study found that most of the 68 cases occurred during the dry season starting from June till September, and the regions of the country (eastern and western provinces) which are the driest were also the most represented amongst the cases. Other studies have also noted that the climate, specifically the dry season, can lead to higher case numbers. ${ }^{20}$ The dryness of the season provides the conditions for destruction of the mucosal defenses thus making individuals more susceptible to meningitis. ${ }^{20}$

According to the pathogens responsible for meningitis, in this study the majority of cases were had a bacterial etiology; specifically Streptococcus pneumonia then Neisseria meningitides $\mathrm{W} 135$. The predominance of these two bacterial agents was also noted as most common in the United States and across other countries globally. ${ }^{1}$ A possible reason for the predominant prevalence of pneumococcal meningitis could be an auto-infection from colonizing bacteria in the nasopharynx. ${ }^{22}$ Auto-transmission from the nasopharynx into the meninges is therefore highly possible especially during the dry season when cracks and injuries tend to occur in the nasopharynx. With the introduction of the pneumococcal vaccine, this prevalence will be reduced in the future as reported in other countries. ${ }^{14}$ In this small sample of cases we only found two cases of $H$. influenzae $B$, which used to be the predominant causative agent. ${ }^{20}$ It is likely that this change was caused by the introduction of Hib vaccines in Rwanda. The impact of the Hib vaccine on the reduction of meningitis has been reported in other countries such as Turkey. ${ }^{22,23,24}$ In this study we identified two cases of Cryptococcus neoformans and one case of candida albicans. It is possible that the cases were amongst patients living with HIV. The prevalence of HIV in Rwanda is $3 \%{ }^{25}$ and meningitis caused by fungi has been reported in other studies amongst those who are immunosuppressed, specifically amongst people living with HIV. ${ }^{26}$

All the bacterial isolates from this study remained susceptible to antibiotics. This findings in some way supports the presumptive treatment of bacterial meningitis prior to identifying the infectious agent. However continued care needs to be taken to monitor drug resistance patterns and alter treatment recommendations accordingly. A low sensitivity rate has been observed to penicillin ranging from 60.3; 55.3, 68.5; 68.2 for $S$. pneumoniae, N. meningitidis W135, E. coli, and $S$. aureus. Those results are similar to others obtained in Madagascar ${ }^{27}$.

\section{Limitations of this study}

The data described is based on reported cases which may not be accurately representative of numbers and distribution of bacterial meningitis cases in Rwanda. Also, this study the relationship between different variables was not considered.

\section{CONCLUSION}

Meningitis is a global health problem and whilst Rwanda is not within the African meningitis belt, cases have been reported. Children under 5 years of age are the most affected and the higher prevalence occurs during dry season, and within the eastern region. Streptococcus pneumoniae was the leading cause of meningitis in this sample and ceftriaxone antibiotic was most active to the majority of identified bacteria. Broad surveillance needs to be conducted to continually assess the nationwide prevalence of meningitis and to document and identify any emerging antimicrobial resistance patterns circulating in Rwanda. Additional studies should consider analyzing the relationship between age, month and location to specific type of pathogens should be analyzed.

\section{REFERENCES}

1. Kinger G, Chin CN, Beyene J, Perlman M. Predicting the outcome of neonatal bacterial meningitis. Pediatrics 2000;106: 47782

2. Kim KS. Pathogenesis of bacterial meningitis: from bacteremia to neuronal injury. Nat Rev Neurosci 2003;4:376 85

3. Shaban L, Siam R. Prevalence and antimicrobial resistance pattern of bacterial meningitis in Egypt. Ann.clin.Microbiol.Antimicrob. 2009 $8(1): 26$

4. Ramakrishnan M, Ulland AJ, Steinhardt LC, Moïsi JC, Were F, Levine OS. Sequelae due to bacterial meningitis among African children: a systematic literature review. BMC Med. 2009; 7:47. doi:10.1186/17417015-7-47.

5. World Health Organisation: Meningitis in Burkina Faso, Chad, Niger, Nigeria and Ghana: 2010 epidemic season. Wkly Epidemiol Rec 2011,86(15):143-151. 
6. Heidi M Soeters, Alpha Oumar Diallo, Brice W Bicaba, Goumbi Kadadé, Assétou Y Dembélé, Mahamat A Acyl, Christelle Nikiema, Adodo Yao Sadji, Alain N Poy, Clement Lingani, Haoua Tall, Souleymane Sakandé, Félix Tarbangdo, Flavien Aké, Sarah A Mbaeyi, Jennifer Moïsi, Marietou F Paye, Yibayiri Osee Sanogo, Jeni T Vuong, Xin Wang, Olivier Ronveaux, Ryan T Novak;, MenAfriNet Consortium, Bacterial Meningitis Epidemiology in Five Countries in the Meningitis Belt of Sub-Saharan Africa, 2015-2017, The Journal of Infectious Diseases, Volume 220, Issue Supplement 4, 1 December 2019, Pages S165-S174, https://doi.org/10.1093/infdis/jiz358

7. Davey, P. 2010. Infections of the central nervous system. Medicine at a Glance 3rd ed. pg 398-406.

8. Gilhus, N. E., Barnes, M. P., and M. Brainin, 2011. Management of community-acquired bacterial meningitis. European handbook of neurological management. Vol. 2.

9. Patel V., A. Woodward, V. L. Feigin, H. K. Heggenhougen, and S. R. Quah, 2010. Mental and Neurological Public Health: A Global Perspective 1st ed. ISBN: 9780123815279

10. Agrawal, S., and S. Nadel, 2011. Acute bacterial meningitis in infants and children: epidemiology and management. Paediatr. Drugs. 13:385400 .

11. The European Union Invasive Bacterial Infections Surveillance Network. Invasive meningococcal disease [Online]. Available from website URL: http://www.ecdc.europa.eu/en/publications/Publications/1011_SUR_A nnual_Epidemiological_Report_on_Communicable_Diseases_in_Euro pe.pdf\#page $=149$. $($ Accessed 01/08/2018).

12. Harrison, L. H., 2010. Epidemiological profile of meningococcal disease in the United States. Clin. Infect. Dis. 50:37-44.

13. Tunkel, A. R., B. J. Hartman, S. L. Kaplan, B. A. Kaufman, K. L. Roos, W. M. Scheld, and R. J. Whitley, 2004. Practice guidelines for the management of bacterial meningitis. Clin. Infect. Dis. 39:1267-1284

14. Sandle, Tim., 2016. Microbial identification. Pharmaceutical Microbiology. P 103-113, ISBN 9780081000229

15. CLSI. Performance Standards for Antimicrobial Susceptibility Testing. 27th ed. CLSI supplement M100.Wayne, PA: Clinical and Laboratory Standards Institute; 2017.

16. Roos, K. L.,. Handbook of clinical neurology: Bacterial infections of the central nervous system. 2010. vol.18 1st Ed - ISBN: 9780444520159

17. Scheld, W. M., U. Koedel, B. Nathan, and H. W. Pfister, 2002 Pathophysiology of bacterial meningitis: mechanism of neuronal injury. J. Infect. Dis. 186:225-233.

18. Gurley, E, S., M. J. Hossain, S. P. Montgomery, L. R. Petersen, J. J. Sejvar, L. W. Mayer, A. Whitney, P. Dull, N. Nahar, A. K. Uddin, M. E. Rahman, A. R. Ekram, S. P. Luby, and R. F. Breiman, 2009. Etiologies of bacterial meningitis in Bangladesh: results from a hospitalbased study. Am. J. Trop. Med. Hyg. 81:475-483.

19. Owusu, M., Nguah, S. B., Boaitey, Y. A., Badu-Boateng, E., Abubakr, A. R., Lartey, R. A., \& Adu-Sarkodie, Y. (2012). Aetiological agents of cerebrospinal meningitis: a retrospective study from a teaching hospital in Ghana. Annals of clinical microbiology and antimicrobials, 11, 28. https://doi.org/10.1186/1476-0711-11-28

20. Thigpen, M. C., C. G. Whitney, N. E. Messonnier, E. R. Zell, R. Lynfield, J. L. Hadler, L. H. Harrison, M. M. Farley, A. Reingold, N. M. Bennett, A. S. Craig, W. Schaffner, A. Thomas, M. M. Lewis, E. Scallan, and A. Schuchat; Emerging Infections Programs Network, 2011. Bacterial meningitis in the United States, 1998-2007. N. Engl. J. Med. 364:2016-2025.

21. Giorgi Rossi, P., J. Mantovani, E. Ferroni, A. Forcina, E. Stanghellini, F. Curtale, and P. Borgia, 2009. Incidence of bacterial meningitis (20012005) in Lazio, Italy: the results of an integrated surveillance system. BMC Infect. Dis. 9:13.

22. Cutts FT, et al: Efficacy of nine-valent pneumococcal conjugate vaccine against pneumonia and invasive pneumococcal disease in The Gambia: randomised, double-blind, placebo-controlled trial. Lancet 2005, 365(9465): 1139-1146.

23. Renner LA, et al: Introduction of Haemophilus influenzae type Bconjugate vaccine into routine immunization in Ghana and its impact on bacterial meningitis in children younger than five years. Pediatr Infect Dis J 2007, 26(4):356-358.

24. Nsanzimana S, Remera E, Kanters S, Mulindabigwi A, Suthar AB, Uwizihiwe JP, et al. Household survey of HIV incidence in Rwanda: a national observational cohort study. Lancet HIV 2017; 4: e457-64. 10.1016/S2352-3018(17)30124-8

25. Arda B, et al: Pooled analysis of 2,408 cases of acute adult purulent meningitis from Turkey. Med Princ Pract 2008, 17(1):76-79.

26. Muyembe Tamfum JJ, et al: Cryptococcosis caused by Cryptococcus neoformans var. Gattii. A case associated with acquired immunodeficiency syndrome (AIDS) in Kinshasa, Zaire. Med Trop (Mars) 1992, 52(4):435-438.

27. Minta DK, et al: Neuromeningeal cryptococcosis in Mali]. Med Trop (Mars) 2011, 71(6):591-595.

Peer Reviewed

Competing Interests: None declared

Received: 13 Jun 2019; Accepted: 27 Apr 2020.

Cite this article as: Musabyumuremyi C, Umuhoza T, Ndoricyimpaye EL, Ntaganira1 G, Tuyiringire N. Etiology Agents and Antibiotic Susceptibility profile of Cerebrospinal Meningitis: Retrospective Description of Surveillance Data in Rwanda. E Afr Sci. 2020;1(2):59-65. http://doi.org/10.24248/EASci-D-19-00005

(C) Musabyumuremyi et al. This is an open-access article distributed under the terms of the Creative Commons Attribution License, which permits unrestricted use, distribution, and reproduction in any medium, provided the original author and source are properly cited. To view a copy of the license, visit http://creativecommons.org/licens- es/by/4.0/. When linking to this article, please use the following permanent link: http://doi.org/10.24248/EASci-D-19-00005 